\title{
OPEN Preventable fractions of cancer incidence attributable to 7-years weight gain in the Norwegian Women and Cancer (NOWAC) study
}

\author{
Marisa da Silva ${ }^{1 凶}$, Maarit A. Laaksonen ${ }^{2}$, Lauren Lissner ${ }^{3}$, Elisabete Weiderpass ${ }^{4,5}$ \& \\ Charlotta Rylander ${ }^{1,5}$
}

There is a lack of tangible measures for directed public health action to halt the increase in weight and cancer. We estimated the fraction and preventable cases of all and major body fatness-related cancers attributable to 7 -years weight gain $(\geq 2 \mathrm{~kg}$ ). We assessed validated self-reported anthropometrics from 44,114 women aged 34-49 years at the enrolment in 1991-1992 and from a second questionnaire in 1998, with follow-up through December 31, 2015. Over 18 years, 3216 body fatness-related cancers and 2041 deaths were reported. Nearly $70 \%$ of women experienced weight gain and the average weight change was $4 \mathrm{~kg}$. We observed a substantial proportional impact of weight gain on pancreatic cancer with a population attributable fraction (PAF) of $41.8 \%(95 \% \mathrm{Cl} 8.1-63.1)$ and a high absolute impact on postmenopausal breast cancer with 4403 preventable cases $(95 \% \mathrm{Cl} 1064-7299)$ and a PAF of $16.8 \%$ (95\% Cl 4.1-27.8), and colorectal cancer with 3857 preventable cases $(95 \% \mathrm{Cl} 1313-5990)$ and a PAF of $22.6 \%$ (95\% Cl 7.7-35.1). Avoiding weight gain over seven years in middle adulthood could have prevented a considerable proportion of the cancer burden and thousands of cancer cases in women in Norway.

Obesity prevalence and cancer incidence have increased worldwide with 13 cancers defined as body fatnessrelated $^{1-3}$. Most studies that have estimated the risk and burden of body fatness-related cancers have used body mass index (BMI) as a proxy for body fatness measured at one point in time $e^{3,4}$. However, weight gain tends to capture increases in fat mass more precisely than BMI and is based on at least two repeated measurements and therefore less prone to misclassification ${ }^{5}$. Adults tend to follow upward weight trajectories ${ }^{6}$ and weight gain has been shown to be independently associated with several cancers ${ }^{7-10}$. Weight change and cancer studies most commonly assess long-term weight change from recalled age at 18 to enrolment, with various designs in relation to sample size, exposure treatment, and follow-up duration. Few studies have assessed short-term weight gain and cancer, and there are uncertainties weather the velocity and magnitude of weight gain is associated with increased cancer risk ${ }^{11}$. Herein, we have assessed weight change from the enrolment to a second questionnaire seven years later.

The fraction of cancer attributable to weight gain has only been evaluated for postmenopausal breast cancer ${ }^{12,13}$, and no study have assessed the fraction of cancer attributable to other than long-term weight change. In a recent paper, we reported that 6-7-years weight gain of $10 \mathrm{~kg}$ or more was associated with increased risk of all body fatness-related cancers, postmenopausal breast cancer, endometrial, and pancreatic cancer in women in Norway ${ }^{8}$. To facilitate translation of these results into relevant public health measures ${ }^{14}$, we herein estimated the fraction of all and major body fatness-related cancers attributable to 7-years weight gain. We used a smaller sub-sample of women in Norway than in our previous publication by only including women from the first wave of enrolment, which allowed us to calculate preventable cancer cases over the follow-up period of 18 years.

\footnotetext{
${ }^{1}$ Department of Community Medicine, Faculty of Health Sciences, UiT The Arctic University of Norway, P.O. Box 6050 Langnes, 9037 Tromsø, Norway. ${ }^{2}$ Centre for Big Data Research in Health, University of New South Wales, Sydney, New South Wales, Australia. ${ }^{3}$ School of Public Health and Community Medicine, Section for Epidemiology and Social Medicine (EPSO), Institute of Medicine, Sahlgrenska Academy, University of Gothenburg, Gothenburg, Sweden. ${ }^{4}$ International Agency for Research on Cancer, World Health Organization, Lyon, France. ${ }^{5}$ These authors contributed equally: Elisabete Weiderpass and Charlotta Rylander. ${ }^{\square}$ email: marisa.da_ silva@med.lu.se
} 


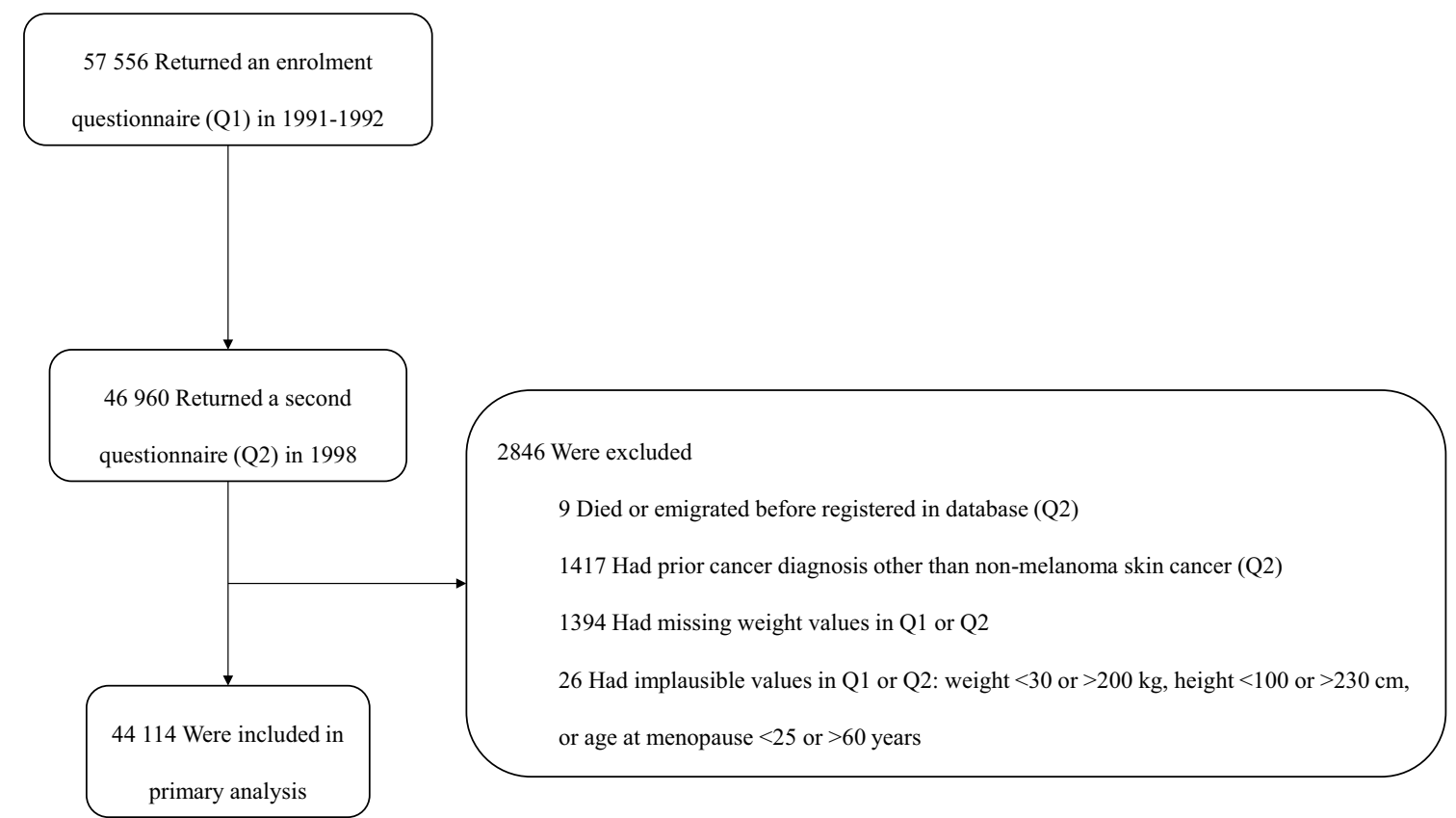

Figure 1. Flowchart of study participants.

\section{Methods}

Study population. The Norwegian Women and Cancer (NOWAC) study is a nationally representative prospective cohort ${ }^{15}$. Women were randomly sampled from the National Registry and were invited to answer consecutive questionnaires with questions on anthropometrics, sociodemographic, lifestyle, and reproductive factors. The unique personal identity number assigned to every resident in Norway allows for complete followup through linkages to national registries ${ }^{16}$. Details on the design of NOWAC have been described elsewhere ${ }^{15}$. In this study, we included women who returned an enrolment questionnaire in 1991-1992 and a second questionnaire in 1998. After exclusions, our final study sample consisted of 44,114 women, aged 34-49 years (Fig. 1).

Follow-up and identification of cancer cases. Follow-up began after the second questionnaire in 1998, hence after the assessed weight change, and continued until cancer diagnosis, death, emigration, or end of study (31 December 2015), whichever occurred first. Incident, invasive, body fatness-related cancers (cancer of the breast [postmenopausal], colon-rectum, endometrium, ovary, pancreas, kidney [renal cell], gallbladder, gastric cardia, liver, oesophagus [adenocarcinoma], thyroid, multiple myeloma, and meningioma) ${ }^{3}$, were identified through linkage to the Cancer Registry of Norway where they were classified according to the International Classification of Diseases 10th Revision. In the analysis of all body fatness-related cancers combined, breast cancer was considered as postmenopausal if a woman reported postmenopausal status in the second questionnaire or had reached 53 years of age before or at breast cancer diagnosis. This age cut off has been used previously in NOWAC and is based on the Million Women Study convention ${ }^{17,18}$. Dates of death and emigration were ascertained through linkage to the Cause of Death Registry and the National Registry, respectively.

Assessment of weight change and confounders. We used self-reported weight in $\mathrm{kg}$ from the enrolment and second questionnaire to calculate weight change over 7.1 (SD 0.6) years. In the analysis of the strength of the association between weight change and body fatness-related cancers, we further categorized weight gain into five groups: weight loss $(<-2 \mathrm{~kg})$, stable weight $(-2$ to $<2 \mathrm{~kg})$, low weight gain $(2$ to $<5 \mathrm{~kg})$, moderate weight gain $(5$ to $<10 \mathrm{~kg})$, or high weight gain $(\geq 10 \mathrm{~kg})$, similar to several previous studies ${ }^{12,19-21}$. In the population attributable fraction (PAF) analysis, we estimated fractions of body fatness-related cancers attributable to weight gain under the scenario that women who gained weight $(\geq 2 \mathrm{~kg})$ had had stable weight $(-2 \mathrm{~kg}$ to $<2 \mathrm{~kg})$.

We used directed acyclic graphs (DAGs) to identify confounding factors ${ }^{22}$. In all analyses, we adjusted for body weight (continuous), age (continuous), education ( $<10$ years/10-12 years/ $>12$ years), physical activity level assessed by self-report on a scale of $1-10$ and collapsed into three categories: (low, $\leq 4 /$ moderate, 5-6/high, $\geq 7$ ), smoking status (never/former/current), alcohol intake ( $\leq$ median/ $>$ median g/day) from the enrolment questionnaire, and physical activity level change (increase/decrease/no change) and smoking status change (cessation/ restart/no change) occurring at any time between the enrolment and second questionnaire. We additionally adjusted for age at menarche ( $\leq$ median/ $>$ median age) in analyses on postmenopausal breast cancer, ovarian, and endometrial cancer, and menopausal status (pre-/peri-/postmenopausal/unknown) in analyses on ovarian and endometrial cancer. We considered diabetes an intermediate variable in the potential causal pathway between weight change and cancer and not a potential confounder ${ }^{23}$. 
Statistical analysis. Population characteristics by cancer cases and non-cancer cases were assessed using $\chi^{2}$ tests for categorical variables and one-way analysis of variance or Kruskal-Wallis test for continuous variables. We used piecewise constant hazard models to estimate hazard ratios (HR) and their 95\% confidence intervals (CI) to analyse the strength of the association between weight change and all and major body fatness-related cancers $^{24}$. Owing to the small number of incident cases, we did not perform site-specific analyses for cancers of the gallbladder, gastric cardia, liver, oesophagus, and thyroid, nor for multiple myeloma or meningioma. We fitted an age-adjusted model and a multivariable model for each outcome. We excluded women with missing information on any of the included variables, and in the site-specific analyses we excluded women who at the second questionnaire were premenopausal (postmenopausal breast cancer analysis) reported hysterectomy (endometrial cancer analysis) or reported bilateral oophorectomy (ovarian cancer analysis). In addition, we tested for interactions on the multiplicative scale between weight change and BMI status in all analyses, hormone therapy (HT) use in postmenopausal breast cancer analysis, and menopausal status in endometrial and ovarian cancer analyses. We used the likelihood ratio test to compare models with and without the interaction terms. In sensitivity analyses, we excluded the first two years as well as the first four years of follow-up to minimize potential reverse causality as weight change can be a symptom of cancer prior to clinical diagnosis.

To calculate the PAF of body fatness-related cancers attributable to 7 -years weight gain, we used a recently developed method ${ }^{25}$ and program ${ }^{26}$ that accounts for death as a competing risk and statistical uncertainty. The method combines the strength of the association between weight gain and cancer, and weight gain and death, as well as the prevalence of weight gain. As the method accounts for death as a competing risk, the possibility of overestimating PAFs is reduced ${ }^{25}$. Further, we multiplied PAF estimates by national incidence figures from 1998 to 2015, which allowed us to estimate the number of cancer cases attributable to weight gain. All analyses were performed using STATA version 15.1 (Stata Corp., College Station, TX, USA) and SAS 9.4 (SAS Institute, Inc., Cary, NC, USA).

Disclaimer. Where authors are identified as personnel of the International Agency for Research on Cancer/ World Health Organization, the authors alone are responsible for the views expressed in this article and they do not necessarily represent the decisions, policy or views of the International Agency for Research on Cancer/ World Health Organization.

Ethics approval. This study was performed in line with the principles of the Declaration of Helsinki. Approval was granted by The Regional Committee for Medical Research Ethics in Northern Norway (P REK NORD 141/2008) and the Norwegian Data Inspectorate.

Consent to participate. All women provided written informed consent for participation and data linkage.

Consent to publish. All women provided written informed consent for publication.

\section{Results}

Exposure prevalence and population characteristics. Between the enrolment and second questionnaire, $69.3 \%$ of women gained weight $(\geq 2 \mathrm{~kg})$ and $24.0 \%$ had stable weight $(-2$ to $<2 \mathrm{~kg})$, the average weight change was 3.9 (SD 5.2) kg. Women who returned the second questionnaire did not differ considerably from women who did not, apart from being less likely to smoke (data not shown). At enrolment, the average age and BMI (SD) were $41.1(4.3)$ years and $23.0(3.3) \mathrm{kg} / \mathrm{m}^{2}$. Women with subsequent body fatness-related cancer were older, heavier, more likely to have less years of education, low physical activity, and to have experienced 7-years weight gain, compared to those without these cancers (Table 1).

Strength of associations. In total, 3216 incident body fatness-related cancers and 2041 deaths were observed over 18 years of follow-up. The average follow-up time and age at diagnosis (SD) were 16.2 (3.1) and 59.8 (5.6) years. Seven years weight gain was associated with all body fatness-related cancers, postmenopausal breast cancer, colorectal, and pancreatic cancer (Table 2). Kidney cancer was also associated with weight gain but with large confidence intervals on both sides of 1 and the analysis was hampered by few cancer cases. Further, there was not enough evidence to confirm an association between weight gain and endometrial and ovarian cancer. We did not find evidence for interactions between weight change and BMI status in any of the analyses, between weight change and HT use in the postmenopausal breast cancer analysis, or between weight change and menopausal status in the endometrial and ovarian cancer analyses. The results did not substantially change by excluding the first two or four years of follow-up, except for colorectal cancer. When excluding the first four years of follow-up, the strength of the association between weight gain and colorectal cancer considerably changed. Therefore, the first four years of follow-up are excluded in all colorectal cancer analyses presented. Further, there were no associations between weight gain and death from causes other than body fatness-related cancers.

Population attributable fractions and preventable cancer cases. The fraction of all body fatnessrelated cancers attributable to 7 -years weight gain ( $\geq 2 \mathrm{~kg}$ ) was $9.3 \%$ (95\% CI 3.5-14.8), which is equivalent to 6859 cancer cases (95\% CI 2562-10 898) (Table 3). The number of all body fatness-related cancer cases attributable to weight gain does not equal the sum of the number of specific body fatness-related cancer cases as there was not enough evidence for an association between weight gain and all site-specific cancers under study. Specifically, $41.8 \%$ of pancreatic cancer cases (95\% CI 8.1-63.1) could have been prevented, should women who gained weight had had stable weight, which corresponds to 1325 cancer cases (95\% CI 258-2001). Under the 


\begin{tabular}{|c|c|c|c|c|}
\hline & \multicolumn{4}{|c|}{ Body fatness-related cancer } \\
\hline & $\mathbf{N}$ & Cases & Non-cases & P-value \\
\hline \multicolumn{5}{|l|}{ Characteristics at the enrolment } \\
\hline Women, $\mathrm{n}$ & 44,114 & 3216 & 40,898 & \\
\hline Age, mean (SD), y & 44,114 & $42.7(4.1)$ & $41.0(4.3)$ & $<0.001$ \\
\hline Weight, mean (SD), kg & 44,114 & $65.0(10.3)$ & $63.7(10.0)$ & 0.040 \\
\hline Height, mean (SD), cm & 44,106 & $167.0(5.6)$ & $166.6(5.5)$ & 0.361 \\
\hline BMI, mean (SD), $\mathrm{kg} / \mathrm{m}^{2}$ & 44,106 & $23.3(3.4)$ & $22.9(3.3)$ & 0.606 \\
\hline BMI, n (\%) & 44,106 & & & \\
\hline Underweight & & $88(2.7)$ & $1429(3.5)$ & \\
\hline Normal weight & & $2349(73.0)$ & $31,023(75.9)$ & \\
\hline Overweight & & $613(19.1)$ & $6775(16.6)$ & \\
\hline Obesity & & $166(5.2)$ & $1663(4.1)$ & $<0.001$ \\
\hline Education, n (\%) & 43,537 & & & \\
\hline$<10$ years & & $743(23.5)$ & $8770(21.7)$ & \\
\hline $10-12$ years & & $833(26.3)$ & $10,017(24.8)$ & \\
\hline$>12$ years & & $1592(50.3)$ & $21,582(53.5)$ & 0.002 \\
\hline Physical activity level, n (\%) & 40,278 & & & \\
\hline Low & & $839(28.3)$ & $9284(24.9)$ & \\
\hline Moderate & & $1215(41.0)$ & $15,710(42.1)$ & \\
\hline High & & $908(30.7)$ & $12,322(33.0)$ & $<0.001$ \\
\hline Smoking status, n (\%) & 44,114 & & & \\
\hline Never smoker & & $1062(33.0)$ & $14,060(34.4)$ & \\
\hline Former smoker & & $976(30.4)$ & $12,559(30.7)$ & \\
\hline Current smoker & & $1178(36.6)$ & $14,279(34.9)$ & 0.121 \\
\hline Alcohol intake, mean (SD), g/day & 43,829 & $3.7(6.5)$ & $3.3(5.5)$ & $<0.001$ \\
\hline \multicolumn{5}{|c|}{ Changes from the enrolment to second questionnaire } \\
\hline Weight change, $\mathrm{n}(\%)$ & 44,114 & & & \\
\hline Weight loss $(<-2 \mathrm{~kg})$ & & $217(6.8)$ & $2755(6.7)$ & \\
\hline Stable weight $(-2$ to $<2 \mathrm{~kg})$ & & $703(21.9)$ & $9872(24.1)$ & \\
\hline Low weight gain $(2$ to $<5 \mathrm{~kg})$ & & $920(28.6)$ & $11,684(28.6)$ & \\
\hline Moderate weight gain $(5$ to $<10 \mathrm{~kg})$ & & $960(29.9)$ & $11,728(28.7)$ & \\
\hline High weight gain $(\geq 10 \mathrm{~kg})$ & & $416(12.9)$ & 4859 (11.9) & 0.031 \\
\hline Physical activity level change, $\mathrm{n}(\%)$ & 38,295 & & & \\
\hline No change & & $1401(49.7)$ & $17,821(50.2)$ & \\
\hline Decrease & & $792(28.1)$ & $9582(27.0)$ & \\
\hline Increase & & $626(22.2)$ & $8073(22.8)$ & 0.442 \\
\hline Smoking status change, n (\%) & 44,114 & & & \\
\hline \begin{tabular}{|l|} 
No change \\
\end{tabular} & & $2662(82.8)$ & $34160(83.5)$ & \\
\hline Restart & & $188(5.9)$ & $2480(6.1)$ & \\
\hline Cessation & & $366(11.4)$ & $4258(10.4)$ & 0.211 \\
\hline
\end{tabular}

Table 1. Population characteristics of participants according to diagnosis of body fatness-related cancer. BMI body mass index, $S D$ standard deviation.

same scenario, $16.8 \%$ of postmenopausal breast cancer (95\% CI 4.1-27.8) and $22.6 \%$ colorectal cancer (95\% CI 7.7-35.1) could have been prevented, translating to 4403 (95\% CI 1064-7299) and 3857 (95\% CI 1313-5990) cancer cases, respectively.

\section{Discussion}

In this nationally representative female cohort, all body fatness-related cancers, postmenopausal breast cancer, pancreatic, and colorectal cancer were attributable to 7-years weight gain. We observed a substantial proportional impact of weight gain on pancreatic cancer and a high absolute impact on postmenopausal breast cancer expressed by the number of preventable cases. The results were independent of weight at enrolment and we did not find evidence that BMI status modified the results. Thus, keeping a stable weight may be of importance irrespective of body weight. There was not enough evidence to confirm an association between weight gain and endometrial, ovarian and kidney cancer. Therefore, the fraction of all body fatness-related cancers is attenuated, which is important to stress in dissemination of the combined estimate. 


\begin{tabular}{|c|c|c|c|c|}
\hline & \multirow[b]{2}{*}{$\mathrm{N}$} & \multirow[b]{2}{*}{ Cancer cases } & \multirow{2}{*}{\begin{tabular}{|l|} 
Age-adjusted model \\
HR $(95 \% \mathrm{CI})$
\end{tabular}} & \multirow{2}{*}{\begin{tabular}{|l|} 
Multivariable model \\
HR $(95 \% \mathrm{CI})$ \\
\end{tabular}} \\
\hline & & & & \\
\hline All body fatness-related cancers ${ }^{a}$ & 37,742 & 2775 & & \\
\hline Weight loss $(<-2 \mathrm{~kg})$ & 2473 & 195 & $1.20(1.02-1.42)$ & $1.12(0.95-1.32)$ \\
\hline Stable weight $(-2$ to $<2 \mathrm{~kg})$ & 9016 & 599 & Reference & Reference \\
\hline Low weight gain $(2$ to $<5 \mathrm{~kg})$ & 10,846 & 801 & $1.13(1.02-1.26)$ & $1.15(1.03-1.27)$ \\
\hline Moderate weight gain $(5$ to $<10 \mathrm{~kg}$ ) & 10,931 & 817 & $1.15(1.04-1.28)$ & $1.13(1.02-1.26)$ \\
\hline High weight gain $(\geq 10 \mathrm{~kg})$ & 4476 & 363 & $1.30(1.14-1.48)$ & $1.22(1.07-1.39)$ \\
\hline Postmenopausal breast cancer $^{\mathrm{b}}$ & 13,074 & 619 & & \\
\hline Weight loss $(<-2 \mathrm{~kg})$ & 892 & 41 & $1.21(0.85-1.72)$ & $1.20(0.83-1.71)$ \\
\hline Stable weight $(-2$ to $<2 \mathrm{~kg})$ & 3118 & 122 & Reference & Reference \\
\hline Low weight gain $(2$ to $<5 \mathrm{~kg})$ & 3736 & 180 & $1.26(1.00-1.58)$ & $1.25(1.00-1.58)$ \\
\hline Moderate weight gain $(5$ to $<10 \mathrm{~kg})$ & 3750 & 185 & $1.30(1.03-1.63)$ & $1.26(1.00-1.59)$ \\
\hline High weight gain $(\geq 10 \mathrm{~kg})$ & 1578 & 91 & $1.57(1.20-2.06)$ & $1.48(1.12-1.96)$ \\
\hline Colorectal cancer $^{\mathrm{a}}$ & 37,742 & 506 & & \\
\hline Weight loss $(<-2 \mathrm{~kg})$ & 2473 & 38 & $1.45(0.96-2.18)$ & $1.40(0.92-2.13)$ \\
\hline Stable weight $(-2$ to $<2 \mathrm{~kg})$ & 9016 & 100 & Reference & Reference \\
\hline Low weight gain $(2$ to $<5 \mathrm{~kg})$ & 10,846 & 156 & $1.49(1.14-1.96)$ & $1.50(1.15-1.97)$ \\
\hline Moderate weight gain $(5$ to $<10 \mathrm{~kg})$ & 10,931 & 153 & $1.42(1.08-1.87)$ & $1.40(1.06-1.84)$ \\
\hline High weight gain $(\geq 10 \mathrm{~kg})$ & 4476 & 59 & $1.45(1.03-2.04)$ & $1.37(0.96-1.94)$ \\
\hline Endometrial cancer $^{c}$ & 35,405 & 269 & & \\
\hline Weight loss $(<-2 \mathrm{~kg})$ & 2311 & 23 & $1.42(0.88-2.29)$ & $1.10(0.66-1.81)$ \\
\hline Stable weight $(-2$ to $<2 \mathrm{~kg})$ & 8485 & 61 & Reference & Reference \\
\hline Low weight gain $(2$ to $<5 \mathrm{~kg})$ & 10,162 & 58 & $0.80(0.56-1.15)$ & $0.86(0.6-1.23)$ \\
\hline Moderate weight gain $(5$ to $<10 \mathrm{~kg}$ ) & 10,276 & 83 & $1.15(0.83-1.60)$ & $1.09(0.78-1.53)$ \\
\hline High weight gain $(\geq 10 \mathrm{~kg})$ & 4171 & 44 & $1.55(1.05-2.29)$ & $1.29(0.86-1.93)$ \\
\hline Ovarian cancer ${ }^{c}$ & 37,052 & 192 & & \\
\hline Weight loss $(<-2 \mathrm{~kg})$ & 2429 & 18 & $1.58(0.91-2.75)$ & $1.43(0.79-2.58)$ \\
\hline Stable weight $(-2$ to $<2 \mathrm{~kg})$ & 8850 & 42 & Reference & Reference \\
\hline Low weight gain $(2$ to $<5 \mathrm{~kg})$ & 10,634 & 52 & $1.04(0.69-1.56)$ & $1.04(0.69-1.57)$ \\
\hline Moderate weight gain $(5$ to $<10 \mathrm{~kg})$ & 10,740 & 61 & $1.22(0.82-1.80)$ & $1.16(0.78-1.74)$ \\
\hline High weight gain $(\geq 10 \mathrm{~kg})$ & 4399 & 19 & $0.95(0.55-1.64)$ & $0.82(0.46-1.48)$ \\
\hline Pancreatic cancer $^{\mathrm{a}}$ & 37,742 & 90 & & \\
\hline Weight loss $(<-2 \mathrm{~kg})$ & 2473 & 5 & $1.42(0.51-3.99)$ & $1.16(0.41-3.30)$ \\
\hline Stable weight $(-2$ to $<2 \mathrm{~kg})$ & 9016 & 13 & Reference & Reference \\
\hline Low weight gain $(2$ to $<5 \mathrm{~kg})$ & 10,846 & 30 & $1.96(1.02-3.77)$ & $2.12(1.10-4.08)$ \\
\hline Moderate weight gain $(5$ to $<10 \mathrm{~kg}$ ) & 10,931 & 31 & $2.04(1.07-3.90)$ & $2.15(1.12-4.12)$ \\
\hline High weight gain $(\geq 10 \mathrm{~kg})$ & 4476 & 11 & $1.86(0.83-4.16)$ & $1.86(0.82-4.21)$ \\
\hline Kidney cancer $^{\mathrm{a}}$ & 37,742 & 85 & & \\
\hline Weight loss $(<-2 \mathrm{~kg})$ & 2473 & 8 & $1.86(0.79-4.34)$ & $1.40(0.59-3.32)$ \\
\hline Stable weight $(-2$ to $<2 \mathrm{~kg})$ & 9016 & 16 & Reference & Reference \\
\hline Low weight gain $(2$ to $<5 \mathrm{~kg})$ & 10,846 & 20 & $1.05(0.55-2.03)$ & $1.13(0.59-2.20)$ \\
\hline Moderate weight gain $(5$ to $<10 \mathrm{~kg}$ ) & 10,931 & 27 & $1.42(0.77-2.64)$ & $1.40(0.75-2.61)$ \\
\hline High weight gain $(\geq 10 \mathrm{~kg})$ & 4476 & 14 & $1.86(0.91-3.81)$ & $1.56(0.75-3.25)$ \\
\hline
\end{tabular}

Table 2. Weight change and risk of body fatness-related cancer. $H R$ hazard ratio, $C I$ confidence interval. ${ }^{a}$ The multivariable model for all body fatness-related cancers, colorectal, pancreatic and kidney cancer included the variables; weight, age, alcohol intake, education, physical activity level, physical activity level change, smoking status, smoking status change. In the colorectal cancer models the first four years of follow-up are excluded. ${ }^{b}$ The multivariable model for postmenopausal cancer were only in women who were postmenopausal at the second questionnaire and included the variables; weight, age, age at menarche, alcohol intake, education,

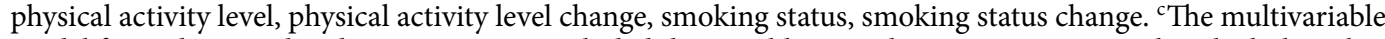
model for endometrial and ovarian cancer included the variables; weight, age, age at menarche, alcohol intake, education, menopausal status, physical activity level, physical activity level change, smoking status, smoking status change. 


\begin{tabular}{|c|c|c|c|c|}
\hline & \multicolumn{2}{|c|}{$\begin{array}{l}\text { Modification of weight gain ( } \geq 2 \mathrm{~kg}) \text { to stable weight }(-2 \mathrm{~kg} \\
\text { to }<2 \mathrm{~kg})\end{array}$} & \multicolumn{2}{|c|}{$\begin{array}{l}\text { Data from the Cancer Registry of Norway, women aged 35-75 years, } \\
1998-2015\end{array}$} \\
\hline & PAF, \%, (95\% CI) & Attributable cancer cases ${ }^{\mathrm{a}},(95 \% \mathrm{CI})$ & Total no. of cancer cases in Norway & $\begin{array}{l}\text { Age-adjusted incidence rate in Norway, } \\
\text { per } 100,000 \text { person-years }\end{array}$ \\
\hline All body fatness-related cancers & $9.3(3.5$ to 14.8$)$ & $6859(2562-10,898)$ & 73,754 & 376 \\
\hline Postmenopausal breast cancer & $16.8(4.1$ to 27.8$)$ & $4403(1064-7299)$ & 26,211 & 268 \\
\hline Colorectal cancer & $22.6(7.7$ to 35.1$)$ & $3857(1313-5990)$ & 17,069 & 87 \\
\hline Endometrial cancer & $2.6(-19.1$ to 20.3$)$ & NA & NA & NA \\
\hline Ovarian cancer & $3.5(-22.9$ to 24.2$)$ & NA & NA & NA \\
\hline Pancreatic cancer & $41.8(8.1$ to 63.1$)$ & $1325(258-2001)$ & 3173 & 16 \\
\hline Kidney cancer & $17.9(-21.2$ to 44.4$)$ & NA & NA & NA \\
\hline
\end{tabular}

Table 3. Population attributable fractions and absolute number of cancer cases attributable to weight gain in women in Norway from 1998 to 2015. Attributable cancer cases were only calculated for outcomes with confidence intervals not including negative values. PAF population attributable fraction, $C I$ confidence

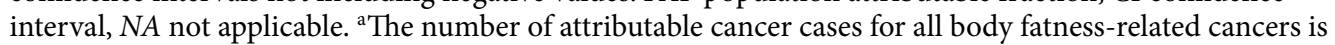
attenuated, as not all site-specific cancers under study were associated with weight gain.

There are two fundamental assumptions from a public health perspective for calculation and interpretation of PAF estimations, the exposure should be causally related to the outcome and the exposure should be amendable to intervention ${ }^{27}$. Causality is imperative as we calculate a counterfactual scenario; how much of a disease burden in a population could be prevented when we hypothetically eliminate the effect of an exposure. Our result suggests that, given a causal relationship, over $40 \%$ of pancreatic cancers could have been prevented, should women who gained weight had had stable weight. The World Cancer Research Fund (WCRF) conducted a systematic literature review on pancreatic cancer and weight change, which they updated in a revised report wherein none of the included studies reported an association ${ }^{28,29}$. Still, WCRF suggests that weight gain is associated with pancreatic cancer, but only as an interrelated aspect with other anthropometrics of body fatness. In addition, two recent studies on weight change and pancreatic cancer also reported null associations ${ }^{9,10}$. There are some plausible explanations to why we found a strong association between weight gain and pancreatic cancer, contrary to that of the literature. We assessed 7-years weight gain to capture rapid accumulation of weight gain, whereas most previous studies have assessed weight change from age 18 to study baseline with a weight follow-up ranging from $\sim 20$ to 50 years within each study. The velocity of accumulated weight gain may have unknown biological implications for cancer development ${ }^{11}$. More specifically, pancreatic cancer development can be related to increased insulin levels and higher bioavailability of insulin-like growth factor ${ }^{30}$, in which short-term weight gain, rather than long-term weight gain, may play a vital role. However, we have found no mechanistic studies that assess short- or long-term weight gain and cancer to confirm or reject this hypothesis. Moreover, in our study, all participants had potentially 18 years of follow-up. A long follow-up time is particularly important when assessing time-to-event data of pancreatic cancer, which has one of the highest median age at diagnosis (72 years in women in Norway) ${ }^{31}$. A study with short follow-up time and a large proportion of young participants will include person-time from individuals in a scenario where it is unlikely for them to have the time to develop pancreatic cancer. Despite relatively few pancreatic cancer cases in our study sample, which limited the precision of the estimates, our result suggest that stable weight can have a large potential for primary prevention of pancreatic cancer. If confirmed in future studies, this result may be of special importance due to the poor prognosis of the disease and given that pancreatic cancer incidence has steadily increased for decades in women in Norway and the US 31,32 .

In our study, postmenopausal breast cancer had a large number of cancers cases attributable to 7-years weight gain, which was expected as it is the most commonly diagnosed cancer in women ${ }^{2,31}$ and the only cancer for which WCRF declare a positive association with weight gain ${ }^{33}$. Further, postmenopausal breast cancer is the only site-specific cancer with reported PAF estimates attributable to weight gain ${ }^{12,13}$. The latest prospective cohort study that calculated fractions of postmenopausal breast cancer attributable to weight gain reported a PAF similar to our result, with comparable strength of association between weight gain and postmenopausal breast cancer, but a higher prevalence of weight gain ${ }^{13}$.

Colorectal cancer also had a large number of cancer cases attributable to 7-years weight gain. Although we excluded the first four years of follow-up to minimize potential reverse causality, we cannot fully rule out that the lower effect estimates in higher weight categories, was due to weight loss as a preclinical symptom of colorectal cancer and resulted in few colorectal cancer cases in these categories. There are uncertainties of the magnitude and period in which unintentional weight loss occurs before colorectal cancer diagnosis, particularly since colorectal cancer can develop over more than 10 years $^{34,35}$. Women in Norway have the highest colon cancer incidence rates in the world, which cannot be explained by established risk factors ${ }^{2}$. Thus, more colorectal cancer studies are warranted, both to disentangle the effect of reverse causality and to elucidate plausible biological mechanisms of weight gain.

Strengths and limitations. The main strength of our study is its large, nationally representative sample of women. The external validity of NOWAC is considered high, as the distribution of exposures is independent of the response rate, and the cumulative incidence of cancer is not substantially different from national figures ${ }^{36}$. 
Moreover, the comprehensive questionnaires enabled us to control for important confounders, and our study design with its long prospective follow-up is critical when investigating body fatness-related cancers that develop later in life. The method that we used accounted for death as a potential competing risk, which may be present in studies with long follow-up and aged participants ${ }^{37}$. Failure to account for death as a competing risk may result in overestimated risk estimates. We estimated 7-years weight change from the enrolment to a second questionnaire, which is different from most studies that have calculated weight change from recalled weight at age 18 to weight at enrolment, which may be prone to recall bias and misclassification as older women would have had a longer period of possible weight gain. Further, we have reported the fraction of body fatness-related cancer burden attributable to weight gain, which is an estimate of the preventable proportion, given a hypothetical intervention. Although the mathematics to calculate this proportion is sound, the intervention must be achievable in the target population for the estimate to fit public health action. In our study, the intervention would be to avoid weight gain over 7-years during middle adulthood, which seems less challenging than weight maintenance from young adulthood through several decades, as in many other weight change studies.

Nevertheless, this study has limitations. Weight was self-reported, and the well-established tendency to underestimate weight that increases with age and BMI, has also been confirmed in NOWAC ${ }^{38,39}$. However, we assume that the potential misclassification was non-differential between women with and without body fatness-related cancers. We also assume that the potential underestimation of weight was similar at the enrolment and the second questionnaire, and that the change in weight was less prone to misclassification. Although, we have adjusted for many important confounders, residual confounding may be present as we could not adjust for medical conditions that affect both weight gain and cancer, time of initiation and frequency for several confounders, nutritional aspects, as the food frequency questionnaire was only provided to a subsample of women, hereditary predisposition, or additional environmental factors that could be related to both weight gain and cancer. Pancreatic and kidney cancer, which were the least commonly reported cancers among the body fatness-related cancers under study, had relatively few cancer cases that led to large confidence intervals. Further, the precision in all PAF analyses was low with large confidence intervals. However, many PAF studies fail in reporting confidence intervals and thus the precision of the estimates is difficult to compare. Consequently, due to the large confidence intervals, the numbers of attributable cancer cases are approximations. The generalisability of our study is limited to Norway. The strength of association between weight gain and cancer may not substantially differ across regions but women in our study sample were slimmer than in many other high-income countries at that time $^{1}$, and thus the exposure prevalence of weight gain and the PAF estimates are likely to be lower in our study.

\section{Conclusions}

Seven-years weight gain in women in middle adulthood had an impact on the burden of all body fatness-related cancers, postmenopausal breast cancer, colorectal and pancreatic cancer. Given a causal relationship, over $40 \%$ of diagnosed pancreatic cancer could have been prevented should women who gained weight had had stable weight. Our study implicates that a substantial proportion of major body fatness-related cancers could have been prevented through weight maintenance and suggests a possible role of the velocity of accumulated weight gain in assessing cancer risk.

\section{Data availability}

The data underlying this article will be shared on reasonable request to the person responsible for the NOWAC study https://uit.no/research/nowac.

\section{Code availability}

The codes used in this article will be shared upon request to the corresponding author.

Received: 3 November 2020; Accepted: 27 January 2021

Published online: 15 February 2021

\section{References}

1. NCD Risk Factor Collaboration. Worldwide trends in body-mass index, underweight, overweight, and obesity from 1975 to 2016: A pooled analysis of 2416 population-based measurement studies in 128.9 million children, adolescents, and adults. Lancet 390(10113), 2627-2642. https://doi.org/10.1016/s0140-6736(17)32129-3 (2017).

2. Bray, F. et al. Global cancer statistics 2018: GLOBOCAN estimates of incidence and mortality worldwide for 36 cancers in 185 countries. CA Cancer J. Clin. 68(6), 394-424. https://doi.org/10.3322/caac.21492 (2018).

3. Lauby-Secretan, B. et al. Body fatness and cancer-viewpoint of the IARC working group. N. Engl. J. Med. 375(8), 794-798. https ://doi.org/10.1056/NEJMsr1606602 (2016).

4. Arnold, M. et al. Global burden of cancer attributable to high body-mass index in 2012: A population-based study. Lancet Oncol. 16(1), 36-46. https://doi.org/10.1016/s1470-2045(14)71123-4 (2015).

5. Hu, F. Obesity Epidemiology (Oxford University Press, New York, 2008).

6. Malhotra, R., Ostbye, T., Riley, C. M. \& Finkelstein, E. A. Young adult weight trajectories through midlife by body mass category. Obesity (Silver Spring, Md). 21(9), 1923-1934. https://doi.org/10.1002/oby.20318 (2013).

7. Keum, N. et al. Adult weight gain and adiposity-related cancers: A dose-response meta-analysis of prospective observational studies. J. Natl. Cancer Inst. https://doi.org/10.1093/jnci/djv088 (2015).

8. da Silva, M., Weiderpass, E., Licaj, I., Lissner, L. \& Rylander, C. Excess body weight, weight gain and obesity-related cancer risk in women in Norway: The Norwegian Women and Cancer study. Br. J. Cancer. 119(5), 646-656. https://doi.org/10.1038/s4141 6-018-0240-5 (2018)

9. Bjørge, T. et al. BMI and weight changes and risk of obesity-related cancers: A pooled European cohort study. Int. J. Epidemiol. 48(6), 1872-1885. https://doi.org/10.1093/ije/dyz188 (2019).

10. Wakamatsu, M. et al. Weight change since age 20 and incident risk of obesity-related cancer in Japan: A pooled analysis of the Miyagi Cohort Study and the Ohsaki Cohort Study. Int. J. Cancer. 144(5), 967-980. https://doi.org/10.1002/ijc.31743 (2019). 
11. Colditz, G. A. \& Peterson, L. L. Obesity and cancer: Evidence, impact, and future directions. Clin. Chem. 64(1), 154-162. https:// doi.org/10.1373/clinchem.2017.277376 (2018).

12. Eliassen, A. H., Colditz, G. A., Rosner, B., Willett, W. C. \& Hankinson, S. E. Adult weight change and risk of postmenopausal breast cancer. JAMA 296(2), 193-201. https://doi.org/10.1001/jama.296.2.193 (2006).

13. Tamimi, R. M. et al. Population attributable risk of modifiable and nonmodifiable breast cancer risk factors in postmenopausal breast cancer. Am. J. Epidemiol. 184(12), 884-893. https://doi.org/10.1093/aje/kww145 (2016).

14. Bray, F. \& Soerjomataram, I. Population attributable fractions continue to unmask the power of prevention. Br. J. Cancer. 118(8), 1031-1032. https://doi.org/10.1038/s41416-018-0062-5 (2018).

15. Lund, E. et al. Cohort profile: The Norwegian Women and Cancer Study-NOWAC-Kvinner og kreft. Int. J. Epidemiol. 37(1), 36-41. https://doi.org/10.1093/ije/dym137 (2008).

16. Lunde, A. S., Lundeborg, S., Lettenstrom, G. S., Thygesen, L., Huebner, J. The person-number systems of Sweden, Norway, Denmark, and Israel. Data evaluation and methods research Hyattsville: U.S. Department of Health and Human Services (1980).

17. Lund, E., Bakken, K., Dumeaux, V., Andersen, V. \& Kumle, M. Hormone replacement therapy and breast cancer in former users of oral contraceptives-The Norwegian Women and Cancer study. Int. J. Cancer. 121(3), 645-648. https://doi.org/10.1002/ijc.22699 (2007).

18. Beral, V. Breast cancer and hormone-replacement therapy in the Million Women Study. Lancet 362(9382), 419-427. https://doi. org/10.1016/s0140-6736(03)14065-2 (2003).

19. Laake, I. et al. A prospective study of body mass index, weight change, and risk of cancer in the proximal and distal colon. Cancer Epidemiol. Biomark. Prev. 19(6), 1511-1522. https://doi.org/10.1158/1055-9965.EPI-09-0813 (2010).

20. Aleksandrova, K. et al. Adult weight change and risk of colorectal cancer in the European Prospective Investigation into Cancer and Nutrition. Eur. J. Cancer. 49(16), 3526-3536. https://doi.org/10.1016/j.ejca.2013.06.021 (2013).

21. Petrick, J. L. et al. Body weight trajectories and risk of oesophageal and gastric cardia adenocarcinomas: A pooled analysis of NIH-AARP and PLCO Studies. Br. J. Cancer. 116(7), 951-959. https://doi.org/10.1038/bjc.2017.29 (2017).

22. Greenland, S., Pearl, J. \& Robins, J. M. Causal diagrams for epidemiologic research. Epidemiology 10(1), 37-48 (1999).

23. Kodama, S. et al. Quantitative relationship between body weight gain in adulthood and incident type 2 diabetes: A meta-analysis. Obes. Rev. 15(3), 202-214. https://doi.org/10.1111/obr.12129 (2014).

24. Friedman, M. Piecewise exponential models for survival data with covariates. Ann. Stat. 10, 101-113 (1982).

25. Laaksonen, M. A., Harkanen, T., Knekt, P., Virtala, E. \& Oja, H. Estimation of population attributable fraction (PAF) for disease occurrence in a cohort study design. Stat. Med. 29(7-8), 860-874. https://doi.org/10.1002/sim.3792 (2010).

26. Laaksonen, M. A., Virtala, E., Knekt, P., Oja, H. \& Härkänen, T. SAS macros for calculation of population attributable fraction in a cohort study design. J. Stat. Soft. 43(7), 25. https://doi.org/10.18637/jss.v043.i07 (2011).

27. Rockhill, B., Newman, B. \& Weinberg, C. Use and misuse of population attributable fractions. Am. J. Public Health. 88(1), 15-19. https://doi.org/10.2105/ajph.88.1.15 (1998).

28. Norat, T., Aune, D., Vieira, A. R., Chan, D., Rosenblatt, D. N., Vieira, R. WCRF/AICR Systematic Literature Review. The Associations between Food, Nutrition and Physical Activity and the Risk of Pancreatic Cancer. (Imperial College London/World Cancer Research Fund, London, 2011).

29. World Cancer Research Fund/American Institute for Cancer Research. Diet, Nutrition, Physical Activity and Pancreatic Cancer. Continuous Update Project Expert Report 2018. (World Cancer Research Fund, London, 2018).

30. Bracci, P. M. Obesity and pancreatic cancer: Overview of epidemiologic evidence and biologic mechanisms. Mol. Carcinog. 51(1), 53-63. https://doi.org/10.1002/mc.20778 (2012).

31. Cancer Registry of Norway. Cancer in Norway 2018-Cancer Incidence, Mortality, Survival and Prevalence in Norway (Cancer Registry of Norway, Oslo, 2019).

32. Gordon-Dseagu, V. L., Devesa, S. S., Goggins, M. \& Stolzenberg-Solomon, R. Pancreatic cancer incidence trends: Evidence from the Surveillance, Epidemiology and End Results (SEER) population-based data. Int. J. Epidemiol. https://doi.org/10.1093/ije/dyx23 2 (2017).

33. World Cancer Research Fund/American Institute for Cancer Research. Body Fatness and Weight Gain and the Risk of Cancer (World Cancer Research Fund International, London, 2018).

34. Wong, C. J. Involuntary weight loss. Med. Clin. N. Am. 98(3), 625-643. https://doi.org/10.1016/j.mcna.2014.01.012 (2014).

35. Brenner, H., Kloor, M. \& Pox, C. P. Colorectal cancer. Lancet 383(9927), 1490-1502. https://doi.org/10.1016/S0140-6736(13)61649 -9 (2014).

36. Lund, E. et al. External validity in a population-based national prospective study-The Norwegian Women and Cancer Study (NOWAC). Cancer Causes Control. 14(10), 1001-1008. https://doi.org/10.1023/b:caco.0000007982.18311.2e (2003).

37. Berry, S. D., Ngo, L., Samelson, E. J. \& Kiel, D. P. Competing risk of death: An important consideration in studies of older adults. J. Am. Geriatr. Soc. 58(4), 783-787. https://doi.org/10.1111/j.1532-5415.2010.02767.x (2010).

38. Nyholm, M. et al. The validity of obesity based on self-reported weight and height: Implications for population studies. Obesity (Silver Spring, Md). 15(1), 197-208. https://doi.org/10.1038/oby.2007.536 (2007).

39. Skeie, G., Mode, N., Henningsen, M. \& Borch, K. B. Validity of self-reported body mass index among middle-aged participants in the Norwegian Women and Cancer study. Clin. Epidemiol. 7, 313-323. https://doi.org/10.2147/clep.s83839 (2015).

\section{Acknowledgements}

We sincerely thank the women who took part in the NOWAC study. The publication charges for this article have been funded by a grant from the publication fund of UiT The Arctic University of Norway.

\section{Author contributions}

M.S., C.R., E.W. and L.L. contributed to the conception of the study and M.S. and C.R. to its design. M.S. performed the statistical analysis and drafted the manuscript. M.L. reviewed the statistical analysis and interpretation of data. M.L., L.L., E.W., and C.R. critically reviewed the manuscript.

\section{Funding}

No funding was received for conducting this study.

\section{Competing interests}

The authors declare no competing interests.

\section{Additional information}

Correspondence and requests for materials should be addressed to M.d.S.

Reprints and permissions information is available at www.nature.com/reprints. 
Publisher's note Springer Nature remains neutral with regard to jurisdictional claims in published maps and institutional affiliations.

(c) (i) Open Access This article is licensed under a Creative Commons Attribution 4.0 International License, which permits use, sharing, adaptation, distribution and reproduction in any medium or format, as long as you give appropriate credit to the original author(s) and the source, provide a link to the Creative Commons licence, and indicate if changes were made. The images or other third party material in this article are included in the article's Creative Commons licence, unless indicated otherwise in a credit line to the material. If material is not included in the article's Creative Commons licence and your intended use is not permitted by statutory regulation or exceeds the permitted use, you will need to obtain permission directly from the copyright holder. To view a copy of this licence, visit http://creativecommons.org/licenses/by/4.0/.

(C) The Author(s) 2021 